\title{
Adult Synovial Sarcoma
}

National Cancer Institute

\section{Source}

National Cancer Institute. Adult Synovial Sarcoma. NCI Thesaurus. Code C7817.

A synovial sarcoma occurring in adults. 